HUOM! Tämä on alkuperäisen artikkelin rinnakkaistallenne. Rinnakkaistallenne saattaa erota alkuperäisestä sivutukseltaan ja painoasultaan.

Käytä viittauksessa alkuperäistä lähdettä:

A. Lagstedt, R. Kauppinen, L. Leite (2021) EDUCATION DIGITALIZATION REQUIRES ECOSYSTEM CHANGE, EDULEARN21 Proceedings, pp. 1246-1251.

https://doi.org/10.21125/edulearn.2021.0306

PLEASE NOTE! This in an electronic self-archived version of the original article. This reprint may differ from the original in pagination and typographic detail.

Please cite the original version:

A. Lagstedt, R. Kauppinen, L. Leite (2021) EDUCATION DIGITALIZATION REQUIRES ECOSYSTEM CHANGE, EDULEARN21 Proceedings, pp. 1246-1251.

https://doi.org/10.21125/edulearn.2021.0306

(C) 2021 IATED. All rights reserved. 


\title{
EDUCATION DIGITALIZATION REQUIRES ECOSYSTEM CHANGE
}

\author{
A. Lagstedt ${ }^{1,2}$, R. Kauppinen ${ }^{1}$, L. Leite ${ }^{3}$ \\ ${ }^{1}$ Haaga-Helia University of Applied Sciences (FINLAND) \\ ${ }^{2}$ Turku School of Economics, University of Turku (FINLAND) \\ ${ }^{3}$ University of Eastern Finland (FINLAND)
}

\begin{abstract}
When digitalizing education, having a new information system is not enough. As always in a digital transformation, the tasks, practices, rules and processes must also be changed. The problem is that too often the technology point of view is stressed, and pedagogical management and organizational change are neglected [1]. However, especially in developing economies, to make successful and sustainable digital transformation in education, even having technological, pedagogical and organizational change is not enough. There must be supporting organizations taking care of implemented solutions and further developing them whenever needed.

In developing economies, there are examples of successful education digitalization projects where new information systems have been taken into use, and the schools have changed their organization and pedagogical approaches. However, after the funding of the development project ends, no one is left to support and maintain the systems. Over time, when problems occur, the system gradually deteriorates. In the worst case, classrooms full of computers are abandoned, although the teachers found the system useful.
\end{abstract}

As a solution, we propose an alternative approach to make sustainable and persistent digital transformation in education. We consider it important to take care of not only information system development (or acquisition) and changes to pedagogy and organization but also the ecosystem supporting the change. The education ecosystem must include organizations getting financial benefits (profits) from taking care of the digitalization operations implemented but also should include those receiving benefits from supporting further development of education digitalization. Therefore, our main research question is: "What is the role of the education ecosystem in education digitalization, and how should it be taken into account in education digitalization projects?"

Building a completely new ecosystem is challenging, and in our proposition several approaches are used to accomplish only the most critical objectives with minimal effort. Firstly, the steps of education digitalization must be understood: not everything is needed at once. In the very beginning, when schools are taking their first steps with education digitalization, there is limited need for expertise and skills. Secondly, supporting organizations do not have to start from scratch. Although there might not be any companies already supporting education digitalization, there might be organizations with enough knowledge to help. Those organizations should be persuaded to test new business models. Thirdly, there are several ways to support local startups and encourage them to find business in the education sector, and here the experiences from other countries can be applied.

In the Eduditra (education digital transformation) project, we have cooperated with two education organizations, Eduix Ltd. (Finland) and Glowdom (Namibia) to start education digital transformation in Namibia. Here we introduce preliminary results and experiences from the first year of our project. We also present preliminary information about new stages of the project.

Keywords: Education, digitalization, ecosystem, sustainable and persistent change.

\section{INTRODUCTION}

Not all education digitalization projects succeed, and if the digitalization is done through foreign aid projects, the success probability is lower. According to Bjørnskov [2] most foreign aid projects fail to make any sustainable improvement, and Djankov et al. [3] are even more pessimistic. They state that foreign aid is mainly harmful, one problem being that the aid never reaches the target, and the money is used undemocratically. As an example, they bring out a study showing that, in an education development project, schools received only $13 \%$ of foreign aid grants awarded by the government [3].

If the aid gets to its destination, the situation is still not without problems. One problem in foreign aid projects is their limited time. It is possible to implement new equipment and processes during the project, 
but too often the results are abandoned quite soon after the project (funding) is over. There have been education digitalization projects in developing economies that have been considered successful, but after a couple of years nothing works anymore, and old practices and processes are taken up again.

The situation being thus, it is important to study how supporting and maintaining the developed digitalization solutions should be organized to achieve sustainable development and stable improvements in education processes and practices. Since the support comes naturally from the education ecosystem, it is essential to understand how the ecosystem works and how it can be developed. The main research question of this research is:

"What is the role of the education ecosystem in education digitalization, and how should it be taken into account in education digitalization projects?"

To get an answer, we consider how school change at the institutional (organizational) level has been investigated, then we present the triple helix (research institutions - government - education digitalization companies) point of view, taking the peculiarities of education digitalization into consideration, and finally we conclude some recommendations for building an education digitalization ecosystem. With this theoretical framework, we have worked on building an education business ecosystem from our ongoing Eduditra (education digital transformation) research project in Namibia. Based on lessons learned, we compose the recommendations to be taken into account when a sustainable ecosystem supporting the change is built.

\subsection{Building business ecosystems}

Ecosystems are loose networks of companies with varying roles; in some cases, companies can cooperate, while in other cases the companies are competitors. In order to be functional, an ecosystem must have some kind of control. Rather often, the role of a leading organization, or a keystone organization, is emphasized [4], [5]. The idea is that in an ecosystem, one dominant organization is orchestrating the innovation, cooperation and offerings of that ecosystem. The keystone organizations get remarkable advantages from ecosystems, but there are high expectations for a keystone organization as well: they must be able to create value efficiently within the ecosystem - for themselves, but for other ecosystem members as well [5]. One way for a keystone organization to produce value for an ecosystem is to provide the tools and the platform to other members. The value a keystone organization creates must be crucial for others [5]. Keystone organizations should also share a vision of the future and common goals for all members of the ecosystem to invest in [4].

As the roles of ecosystems change case by case, it is important to have common tools and practices to evaluate each situation and value proposition of all potential cooperation partners. To support the changing situation of ecosystems, Talmar et. al [6] have developed an ecosystem pie model, which can be used when each case and the value proposition is evaluated. The main elements of the ecosystem pie model are the evaluation of the company's resources, activities needed for a case, value the company adds to the case and value the company gets from the case. With these four factors, it is possible to evaluate who should be involved, what kind of value they produce and what their share is. The aim is to find an optimal combination of actors where all members get enough value and the risks are minimized [6]. Tools such as the pie model are important assets for an ecosystem to produce competitive solutions and to get to know each other better.

\subsection{Government - academia - industry cooperation}

When new ecosystems and tools supporting them are considered, it is important to understand the different roles and positions of different actors. For that, a triple helix model (see Figure 1) is a practical tool. Etzkowitz and Leydesdorff [7] pointed out that the relationships of university, industry and government - the three helixes - are important in innovation and knowledge transfer. 


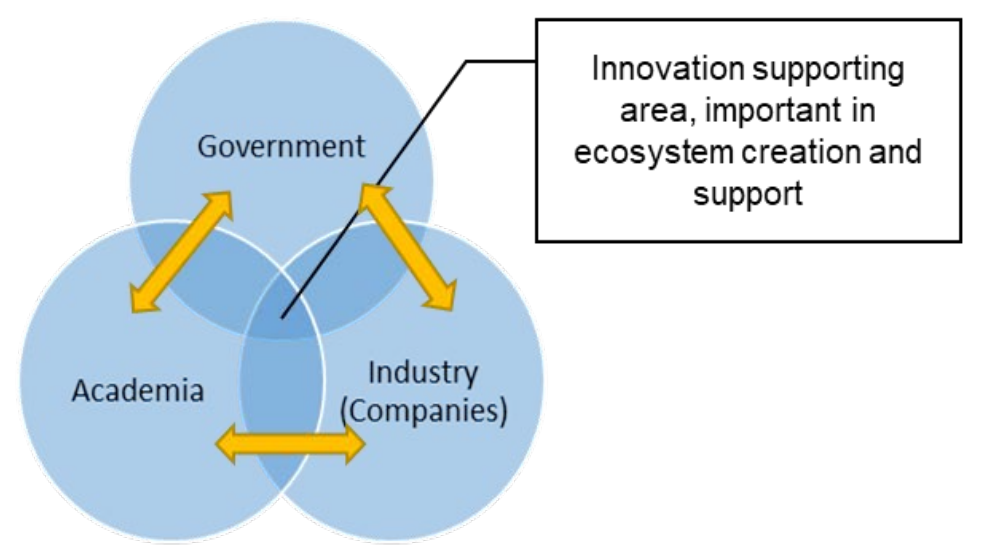

Figure 1. The Triple Helix model (Etzkowitz and Leydesdorff, 2000).

There are certain roles for government, research institutions and companies, and each "helix" has its own responsibilities: government can allocate funding for institutions to research certain areas important to the new ecosystem, and government can also support companies through funding, as well as legislation and other ways, to move to a new industry (ecosystem).

Academia (research institutions and higher education institutions) in turn should co-create new practices and solutions in shared research projects with industry; generate recommendations and propositions for industry and government; offer communication channels (for example, seminars) for different stakeholders to meet, innovate and co-create; and update teacher education to support the digital transformation of education.

Companies are self-evidently in the center of ecosystem building. It is important that companies of the new ecosystem closely cooperate with research institutions and government. In that way companies will obtain business opportunities, funding, reseach and development resources (from research institutions), skills and competences (from research institutions and learning while doing), different kinds of cooperation forums and platforms, and improved reputation and credibility. Of course, all this is not totally free, companies must be ready for real cooperation with research institutions and allocate resources for that as well.

\subsection{Education digitalization at the institutional level}

When we focus the investigation of ecosystem building at the institutional level, there is no widely accepted (and scientifically valid) model of how education digitalization should be done, especially how change should be managed both at the organizational (school) and individual (teacher) levels. There are, however, several well-known independent theories and approaches regarding the phenomenon of integrating technology at work and, specifically, in educational settings, such as UTAUT (the unified theory of acceptance and use of technology) [8], TPACK (the technological, pedagogical and content knowledge) [9], and EXOD (the expert-oriented digitalization) model [10].

These and other previous works were revised by Leite and Lagstedt [11] and compared to their conceptual CIT (collective integration of technology) model. The CIT model supports schools in digitalizing their teaching, primarily to make remote education possible due the COVID-19 pandemic. It considers the collective process of knowledge building of a group (teachers, heads of office, principals, etc.) and how the learning culture of the organization can support (or hinder) EdTech (education technology) integration into school practices. According to CIT, teachers who needed to rapidly integrate EdTech to provide remote education entered into a journey of changes involving different processes: behavioral (strategies to deal with the changes brought by EdTech integration), emotional (feelings related to the changes), and cognitive (learning). At the same time, teachers were being constantly influenced by the shared experiences of the school group and how leaders were guiding them through the processes of change. All these aspects were distinguished in four main states, which can guide school leaders making decisions to manage organizational change accordingly: shock (disruptive and intense learning), negotiation (familiarization and goal setting), empowerment (confidence and application), and explorer state (innovating work practices). 


\section{METHODOLOGY}

The method used is based on ADR (action design research), consisting of four stages (Sein et al. 2011): 1) problem formulation, 2) building, intervention and evaluation, 3) reflection and learning, and 4) formalization of learning. Here, the trigger for stage one (problem formulation) has been problems perceived in education digitalization - for example, difficulties in building a sustainable education ecosystem that is actually brought into use and maintained after the initial effort to build and introduce it.

Based on stage one, steps to build a sustainable education ecosystem have been taken in stage two (building, intervention and evaluation) in the Eduditra project in cooperation with the participating companies and stakeholders, leading to the first intervention in the digital transformation of education. The results of this intervention are currently under further study (stage three, reflection and learning) and formulated (stage four, formalization of learning), for example, in this paper, leading to additional interventions, reflection and formalization and, if necessary, problem reformulation.

In this study, we briefly considered the know-how and experiences of relevant Namibian stakeholders, such as company founders, researchers, teachers and university lecturers, school principals and change agents, software developers, and innovation center representatives, among others, who have a crucial role in building the education business ecosystem in the country.

The stakeholders' contributions were compiled from a webinar series organized by Eduix and Glowdom during the year 2020. The webinar series included five episodes with the following themes: 1) Digitizing education management in emerging markets [12]; 2) Digitizing teaching practices amid the COVID-19 pandemic in Namibia [13]; 3) Education in the world 4.0: bridging the gap between education and the market [14]; 4) Systematic data for decision-making: transnational experiences [15]; and 5) E-teaching: the TPACK framework and Flipped Classroom [16].

\section{RESULTS}

According to the related work presented in the Introduction, in which we briefly reviewed school institutional change, the triple helix model (explaining the ecosystem supporting school change), and how building a business ecosystem involves flexible and changing roles of companies, we can summarize that building an education ecosystem involves different stakeholders at different levels. The participants in the webinar series shared their experiences regarding the different roles they play in transforming education towards building a digital business education ecosystem. Below we highlight some of the participants' insights.

Starting from the educational institution perspective, Eduix's consultant emphasized that digitizing education management at the school level is relevant because digital data gives more transparency, accuracy, and security to decision-making on pedagogical and management matters. Because data is collected and analyzed over time, administrators can monitor and track better teacher performance, student learning and coordinators' tasks. Integrating technology can be chaotic and bring stress [11], but it can be very well done if managed stepwise and if stakeholders feel control over the changes.

Taking the perspective of building a digital education ecosystem, Glowdom's founder and its program manager considered a few cultural and infrastructure factors in Namibia that might interfere in in this process: the population's pessimistic mindset towards digital solutions and the lack of adequate resources for the implementation of EdTech solutions, such as internet connectivity, proper devices and skilled personnel capable of using digital solutions in education. Based on this situation analysis, they considered that, at the government administrative level, decision makers need more updated and accurate data about the actual infrastructure and conditions of municipalities, so they can allocate the needed resources (computers, internet connectivity, pre-service and in-service personnel training, etc.) that support efficient technology integration into education processes.

Further, NBIl's (the Namibian Business Innovation Institute) head of innovation highlighted how NBII, as an academic institution, has the fundamental role of matching industry needs with the development of students' (future workers') competences. He noted the institution is trying to access the market needs, so they can, together with curriculum designers and lecturers, develop meaningful education to promote the skills that future workers will need to match the labor market. The head of innovation further stressed that one of the main challenges in Namibia is that there is no regional- or national-level strategy for building a digital education ecosystem.

Besides organizing webinars, Glowdom and Eduix have also trained 168 Namibian K-12 teachers to apply remote teaching during the COVID-19 pandemic [11]. Currently, we are investigating the 
impacts of the training program on teachers' digital skills for improving (remote) education, together with factors that are needed for a successful implementation of digital solutions with different stakeholders at different levels of the ecosystem.

\section{DISCUSSION AND CONCLUSIONS}

Based on the findings of previous studies, as well as observations from the ongoing Eduditra project, we claim that the supporting ecosystem has a remarkable role in digital transformation of education. Without it, there is no guarantee of the changes' sustainability, no maintenance of systems nor responsible organizations or actors of future development. Governments and research institutions should have an active role when the supporting ecosystem is built. This is our answer to the first part of the research question: "What is the role of the education ecosystem in education digitalization, and how should it be taken into account in education digitalization projects?"

Based on the findings of webinars and training sessions for the ongoing Eduditra project, we state that education ecosystem building and education digitalization should happen simultaneously, and the different phases of the CIT model should be applied each digitalization development cycle to assemble the knowledge needed for the change. Thus, as an answer to the second part of the research question ("and how should it be taken into account in education digitalization projects?"), we recommend that both education digital transformation and the ecosystem supporting it should be developed in small, iterative steps. The development should be started with small government-supported pilots together with schools, research institutes and EdTech companies. As soon as there are good results to be shared, more stakeholders should be involved, the solution should be scaled and the next iteration cycle started.

In addition, based on the preliminary results of the Eduditra project, we conclude that there is a huge need for guidelines on where and how to start the digital transformation. Rather easily, the situation can be considered a chicken and egg strategy problem. For example, some might say that teachers are reluctant to use new technology because they do not have enough technical skills - and they do not have enough technical skills because new technology is not available. To tackle these issues, a clear education digitalization and ecosystem-building roadmap is needed, and we see it as important to develop a more comprehensive model for roadmap building in future studies.

\section{ACKNOWLEDGEMENTS}

The Eduditra project is funded by Eduix Ltd.

\section{REFERENCES}

[1] F. Pettersson, "Understanding digitalization and educational change in school by means of activity theory and the levels of learning concept," Educ. Inf. Technol., pp. 187-204, 2020.

[2] C. Bjørnskov, "Types of Foreign Aid," in Lessons on Foreign Aid and Economic Development, N. Dutta and C. R. Williamson, Eds. Cham: Palgrave Macmillan, 2019, pp. 33-61.

[3] S. Djankov, J. G. Montalvo, and M. Reynal-Querol, "The curse of aid," J. Econ. Growth, vol. 13, no. 3, pp. 169-194, 2008.

[4] S. Rinkinen and V. Harmaakorpi, "The business ecosystem concept in innovation policy context: building a conceptual framework," Innov. Eur. J. Soc. Sci. Res., vol. 31, no. 3, pp. 333-349, 2018.

[5] M. lansiti and R. Levien, "Strategy as Ecology," Harv. Bus. Rev., vol. March, pp. 68-78, 2004.

[6] M. Talmar, B. Walrave, K. S. Podoynitsyna, J. Holmström, and A. G. L. Romme, "Mapping, analyzing and designing innovation ecosystems: The Ecosystem Pie Model," Long Range Plann., vol. 53, no. 4, 2020.

[7] H. Etzkowitz and L. Leydesdorff, "The dynamics of innovation: From National Systems and 'mode 2 ' to a Triple Helix of university-industry-government relations," Res. Policy, vol. 29, no. 2, pp. 109123, 2000.

[8] V. Venkatesh, M. G. Morris, G. B. Davis, and F. D. Davis, "User acceptance of information technology: Toward a unified view," MIS Q. Manag. Inf. Syst., vol. 27, no. 3, pp. 425-478, 2003. 
[9] P. Mishra and M. J. Koehler, "Technological Pedagogical Content Knowledge: A Framework for Teacher Knowledge," Teach. Coll. Rec., vol. 108, no. 6, pp. 1017-1054, 2006.

[10] A. Lagstedt, J. P. Lindstedt, and R. Kauppinen, "An outcome of expert-oriented digitalization of university processes," Educ. Inf. Technol., 2020.

[11] L. Leite and A. Lagstedt, "The Collective Integration of Technology (CIT) Model: Helping Teachers Incorporate Technology Meaningfully in Their Everyday Work," to be Publ.

[12] Eduix Itd, "Episode 1: Digitizing education management," Webinar Series: Eduix and Glowdom leveraging the digital ecosystem for education in Namibia, 2020. [Online]. Available: https://www.youtube.com/watch?v=8VOTDIwW7yl\&t=2424s

[13] Eduix Itd, "Episode 2: Digitizing the teaching practice amid the Covid-19 pandemic in Namibia," Webinar Series: Eduix and Glowdom leveraging the digital ecosystem for education in Namibia, 2020. [Online]. Available: https://www.youtube.com/watch?v=gnfeiymzZug\&t=16s

[14] Eduix Itd, "Episode 3. Education in the world 4.0: bridging the gap between education and the market," Webinar Series: Eduix and Glowdom leveraging the digital ecosystem for education in Namibia, 2020. [Online]. Available: https://www.youtube.com/watch?v=0OELbpKyMYo\&t=350s

[15] Eduix Itd, "Episode 4. Systematic data for decision making: transnational experiences," Webinar Series: Eduix and Glowdom leveraging the digital ecosystem for education in Namibia, 2020. [Online]. Available: https://www.youtube.com/watch?v=YQToRBpvmwk\&t=5s

[16] Eduix Itd, "Episode 5. E-teaching: the TPACK (technological, pedagogical, content knowledge) framework and Flipped Classroom," Webinar Series: Eduix and Glowdom leveraging the digital ecosystem for education in Namibia, 2020. [Online]. Available: https://www.youtube.com/watch?

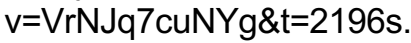

